\title{
Cantilevered Bedtime Story
}

Wallpaper farm, the girl

with the ducks, the friendly

farmer's father-work, the moony mother's queer stare and the bee-hivey haystacks, the pitchforks, the curly cows by the pond.

Elsewhere, a window frames green light. Elsewhere, the dark-hall-doorway, the long walk to the kitchen's grown-up talking. The Singer in the corner, electric and shiny and under the bed, and under the bed...

O happy wallpaper-girl, the cow wants to give you her milk. The father's pitchfork is solid and serene, but what can be done for the woman in the fluttering apron whose gaze is seaward, and elsewhere, and gone? 